\title{
Pengaruh Kompensasi Motivasi dan Kepuasan Kerja terhadap Kinerja Karyawan PT. Kurnia Mandiri Jaya pada Divisi Distribusi Kantor Pusat di Cirebon
}

\author{
Jefta Andika Kurniawan dan M.Tony Nawawi \\ Program Studi Manajemen Fakultas Ekonomi \& Bisnis \\ Universitas Tarumanagara \\ Email: jefta.andika@gmail.com
}

\begin{abstract}
This research aims to analyse the influence of compensation, motivation, and job satisfaction on the performance of employees at PT Kurnia Mandiri Jaya in the distribution division of the head office in Cirebon. The method used in this research is the quantitative method as a research method based on the philosophy of positivism, used to examine on certain populations or samples, data collection using research instruments, quantitative data analysis/statistics, with the aim to test a predetermined hypothesis. The population in this research is a permanent employee of PT. Kurnia Mandiri Jaya amounting to 107 employees. Determining the number of samples is done using the non-probability sampling method by using a saturated sampling which means the population is the number of samples. The data used in this research is the primary data questionnaire in which the subject of his research is 107 permanent employees of PT. Kurnia Mandiri Jaya Cirebon. Hypothesis testing using Partial Least Square Structural Equation Modeling. The results show that compensation, motivation and job satisfaction have a positive and significant impact on employee performance.
\end{abstract}

Keywords: Compensation, Motivation, Job Satisfaction, Employee Performance.

Abstrak :Penelitian ini bertujuan untuk menganalisis pengaruh kompensasi, motivasi, dan kepuasan kerja terhadap kinerja karyawan di PT Kurnia Mandiri Jaya pada divisi distribusi kantor pusat di cirebon. Metode yang digunakan dalam penelitian ini adalah Metode kuantitatif sebagai metode penelitian yang berlandaskan pada filsafat positivisme, digunakan untuk meneliti pada populasi atau sampel tertentu, pengumpulan data menggunakan instrument penelitian, analisis data yang bersifat kuantitatif/statistik, dengan tujuan untuk menguji hipotesis yang telah ditetapkan. Populasi dalam penelitian ini adalah karyawan tetap PT. Kurnia Mandiri Jaya berjumlah 107 pekerja. Penentuan jumlah sampel dilakukan dengan menggunakan metode non-probability sampling dengan menggunakan sampling jenuh yang berarti populasi adalah jumlah sampel. Data yang digunakan dalam penelitian ini adalah data primer berupa kuesioner dimana subjek penelitiannya adalah 107 karyawan tetap PT. Kurnia Mandiri Jaya Cirebon. Pengujian hipotesis menggunakan Partial Least Square Structural Equation Modeling. Hasil penelitian menunjukkan bahwa kompensasi, motivasi dan kepuasan kerja berpengaruh positif dan signifikan terhadap kinerja karyawan.

Kata Kunci : Kompensasi, Motivasi, Kepuasan Kerja, Kinerja Karyawan.

\section{LATAR BELAKANG}

Sering dijumpai beberapa karyawan yang memilki performa yang rendah ataupun menurun. Karyawan yang memiliki kinerja kurang baik dalam suatu perusahaan ataupun menurunnya performa karyawan tentunya akan menghambat dalam pencapaian tujuan 
perusahaan. Fenomena tersebut juga terjadi di PT. Kurnia Mandiri Jaya, seperti yang diungkapkan oleh pihak HRD yang memberikan perhatian pada tidak tercapainya standar kerja pada beberapa karyawan. Penurunan kinerja disebabkan oleh faktor yang sangat komplek, dari perspektif karyawan bisa dimungkinkan karena berbagai faktor yang mendasari seperti motivasi kerja, kompensasi, kompetensi, komitmen karyawan kepuasan kerja dan berbagai faktor lainnya.

\section{KAJIAN TEORI}

Definisi kompensasi. adalah penghargaan atau ganjaran pada para pekerja yang telah memberikan kontribusi dalam mewujudkan tujuannya, melalui kegiatan yang disebut bekerja menurut Nawawi (2011:314). Menurut Fernando dan Thevaranjan (2017:49) Kompensasi merupakan insentif berupa uang tunai umumnya terkait dengan kinerja karyawan, selain itu penghargaan bonus biasanya didasarkan pada ukuran kinerja jangka pendek.

Definisi motivasi. menurut Siagian (2013: 138)adalahdaya dorong yang mengakibatkan seseorang anggota organisasi mau dan rela untuk mengerahkan kemampuan dalam bentuk keahlian atau ketrampilan, tenaga dan waktunya untuk menyelesaikan berbagai kegiatan yang menjadi tanggung jawabnya dan menunaikan kewajibanya dalam rangka pencapaian tujuan dan berbagai sasaran organisasi yang telah ditetapkan sebelumnya.Winardi (2015:322) mengemukakan bahwa, motivasi dapat didefinisikan sebagai hal yang menyebabkan, menyalurkan, dan mendukung perilaku manusia, supaya mau bekerja giat dan antusias guna mencapai hasil yang optimal.

Definisi kepuasan kerja. menurut Rivai (2013:856)adalahevaluasiyang menggambarkan seseorang atas perasaan sikapnya senang atau tidak senang, puas atau tidak puas dalam bekerja.

Definisi kinerja karyawanmenurut Mangkunegara, (2013) adalah kinerja merupakan hasil kerja secara kualitas dan kuantitas yang dicapai oleh seorang pegawai dalam melaksanakan tugasnya sesuai dengan tanggung jawab yang diberikan kepadanya.

Dalam penelitian ini, peneliti ingin mencari tahu apakah ada pengaruh antara kompensasi, motivasi, kepuasan kerja, terhadap kinerja karyawan. Dalam penelitian yang dilakukan oleh Okwudili dan Ogbu, (2017) telah membuktikan bahwa kompensasi langsung dan tidak langsung, akan meningkatkan kinerja karyawan, dengan hasil yang menyatakan bahwa kompensasi berpengaruh signifikan terhadap kinerja karyawan. sedangkan penelitian lain yang dilakukan oleh (Nawawi, 2015; Olusadum dan Anulika, 2018; Nikensari et al, 2018) membuktikan bahwa motivasi kerja memiliki dampak yang signifikan terhadap kinerja karyawan.

Beberapa hasil studi juga membuktikan bahwa kepuasan kerja berpengaruh signifikan terhadap kinerja karyawan (Inuwa, 2016; Panchal, 2016; Nawawi, 2015).

\section{Hipotesis Penelitian}

Hipotesis yang dikembangkan melalui tujuan penelitian yang telah diuraikan pada bagian sebelumnya dan kerangka konseptual yaitu:

H1 : Kompensasi berpengaruh signifikan terhadap kinerja karyawan

H2 : Motivasi kerja berpengaruh signifikan terhadap kinerja karyawan

H3 : Kepuasan kerja berpengaruh signifikan terhadap kinerja karyawan 
Berdasarkan kajian pustaka dan kaitan antar variabel, dapat dikembangkan model penelitian sebagai berikut:

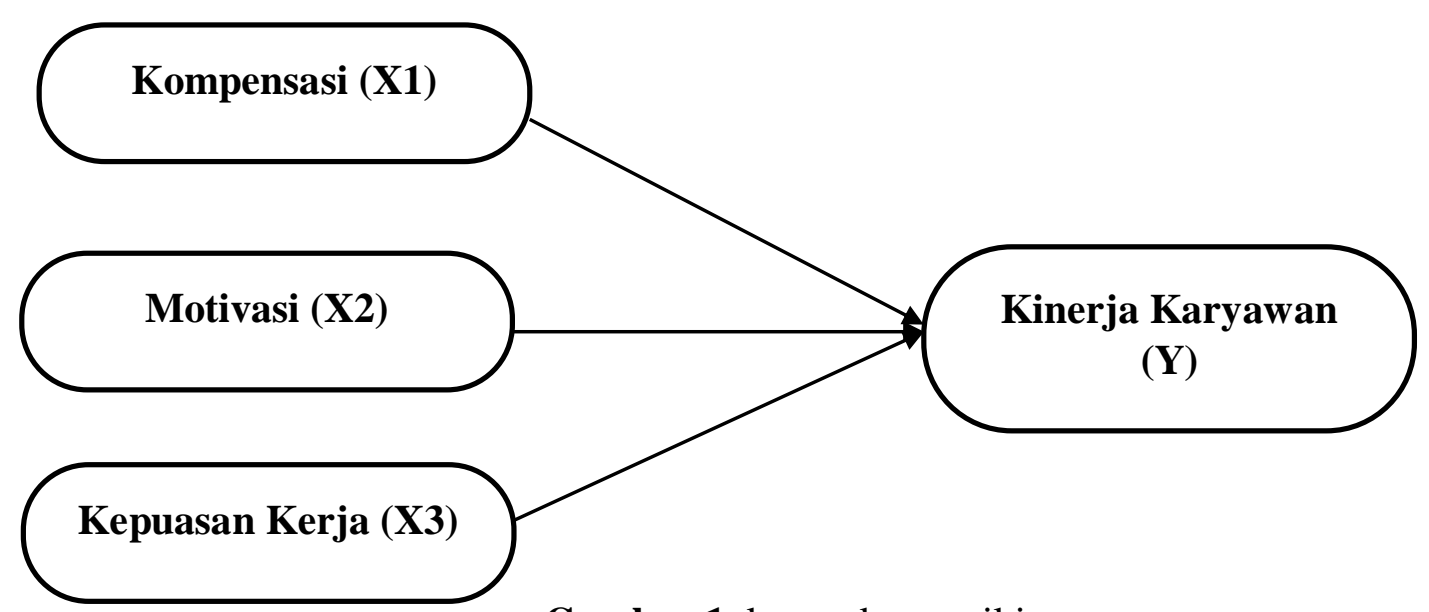

Gambar 1. kerangka pemikiran

\section{METODOLOGI}

Desain Penelitian. Penelitian ini menggunakan pola pendekatan kuantitatif. Mengenai pendekatan kuantitatif, Sugiyono (2017:8) mengemukakan bahwa: "Metode penelitian kuantitatif dapat diartikan sebagai metode penelitian yang berlandaskan pada filsafat positivisme, digunakan untuk meneliti pada populasi atau sampel tertentu, pengumpulan data menggunakan instrument penelitian, analisis data yang bersifat kuantitatif/statistik, dengan tujuan untuk menguji hipotesis yang telah ditetapkan". Melalui penerapan metode kuantitatif diharapkan peneliti mendapatkan informasi yang tepat dan akurat serta gambaran korelasi dari pengaruh Kompensasi (X1),Motivasi (X2), dan Kepuasan kerja (X3) terhadap Kinerja Karyawan (Y).

Menurut Sugiyono (2016:16) penelitian kausalitas adalah penelitian yang dilakukan untuk mengetahui hubungan yang bersifat sebab akibat. Dalam penelitian kausal terdapat variabel independen (variabel yang mempengaruhi) dan variabel dependen (dipengaruhi). Penelitian ini dilakukan untuk mengetahui dampak Pendidikan dan karakter terhadap minat berwirausaha

Populasi, Teknik Pemilihan Sampel, dan Ukuran Sampel. Populasi adalah wilayah generalisasi yang terdiri atas: obyek/subyek yang mempunyai kualitas dan karakteristik tertentu yang ditetapkan peneliti untuk dipelajari kemudian ditarik kesimpulannya (Sugiyono, 2017:80). Populasi dapat juga disebut sebagai sekumpulan unsur atau elemen yang menjadi objek penelitian, atau himpunan semua yang ingin diketahui. Adapun populasi dalam penelitian ini adalah karyawan tetap PT. Kurnia Mandiri Jaya di Cirebon berjumlah 107 orang.

Sampel adalah bagian dari jumlah dan karakteristik yang dimiliki oleh populasi. Bila populasi besar dan peneliti tidak mempelajari semua yang ada pada populasi (keterbatasan dana, tenaga dan waktu) maka peneliti dapat menggunakan sampel yang diambil dari populasi itu (Sugiyono, 2017:81).Metode sampel yang digunakan adalah sampel nonprobability sampling. Cara atau teknik pengambilan sampel di atas dilakukan dengan metode sampling jenuh. 
Dalam penelitian ini jumlah sampel yang akan digunakan adalah 107 responden. Tujuan digunakan jumlah responden yang lebih banyak iyalah agar bila terjadi atau terdapat data yang bias atau tidak valid, maka hal tersebut tidak akan mengurangi jumlah respon di bawah sampel minimum dan sampel pada penelitian ini adalah karyawan tetap PT. Kurnia Mandiri Jaya.

\section{HASIL UJI STATISTIK}

Analisis Data. Analisisdata dalam penelitian ini menggunakan analisis regresi berganda dengan bantuan program SmartPLS 3.2.8. Dengan pengujian instrumen penelitian, uji asumsi klasik (uji validitas, uji reliabilitas, uji Gof, dan uji t-statistik).

Hasil Uji Validitas Instrumen Penelitian. Dalam penelitian ini, pengujian validitas dilakukan secara instrument yang ada didalam aplikasi PLS 3.2.8. Peneliti melakukan pengujian validitas instrument dalam PLS yang menggunakan validitas konvergen. Validitas konvergen terdiri atas nilai factor loading (Outer Loading) dan average variance extracted serta pengujian validitas dapat diukur melalui Fornell-Larcker criterion dan cross loading. Nilai suatu indicator memiliki nilai $>0,6$ dengan pernyataan cukup dan $>0,7$ dengan pernyataan tinggi

Hasil Uji Reliabiltas Instrumen Penelitian. Uji reliabilitas dilihat melalui nilai compositereliability setiap pertanyaan dengan syarat nilai CR lebih besar atau sama dengan 0,70 maka pertanyaan atau pernyataan untuk mengukur variabel tersebut dapat diterima (Hussein, Ananda Sabil, 2015) dan nilai cronbach's alpha > 0,60 maka reliabel dan apabila nilai cronbach's alpha $<0,60$ maka tidak reliabel (Abdillah.W dan Jogiyanto, 2015). Berikut merupakan tabel mengenai nilai Composite reliability danAlpha Cronbach.

Hasil Uji $\boldsymbol{R}$-squareKoefisien Determinasi $\left(\mathbf{R}^{\mathbf{2}}\right)$. Mustafa dan Wijaya, (2012) menyatakan bahwa koefisien determinasi $\mathrm{R}^{2}$ (regresi berganda) adalah koefisien yang memberi tahu seberapa baik sampel garis regresi yang sesuai dengan data yang dimiliki'. R Square yang mendekati 1 menunjukkan model yang semakin baik. Dengan demikian model penelitian ini sudah dapat dikategorikan baik yang mana variabel kompensasi, motivasi kerja dan kepuasan kerja sudah mampu menjelaskan variabel kinerja karyawan sebesar 87,4\%.

Hasil Uji Goodness of Fit. Malhotra (2015:366) menyatakan bahwa tingkat kelayakan model atau dikenal sebagai Goodness of Fit (GoF) digunakan untuk mengevaluasi model struktural (inner model) dan model pengukuran (outer model). Menurut Malhotra (2015:366), Goodness of fit (Goodness of fit) ini menunjukkan bahwa seberapa baik model yang sudah ditentukan ini agar sesuai dengan data yang akan diamati atau sampel yang dipilih. Menurut Schepers et al., (2008), kriteria nilai GoF yaitu GoF rendah (0.1), GoF sedang (0.25), dan GoF tinggi (0.36).

$$
\begin{aligned}
& \overline{A V E}=\frac{0.751+0.740+0.748+0.746}{4}=0.74625 \\
& \overline{R^{2}}=0.874 \\
& G o F=\sqrt{\overline{A V E} x \overline{R^{2}}} \\
& \text { GoF }=\sqrt{0,74625 \times 0,874}
\end{aligned}
$$




\section{$G o F=0,807$}

Berdasarkan hasil perhitungan nilai goodness of fit tersebut, maka dapat disimpulkan bahwa model yang digunakan pada penelitian ini memiliki goodness of fit atau kecocokan model penelitian yang tergolong kategori tinggi karena nilai GoF yang dihasilkan lebih dari 0,36 .

Path Coefficients (Koefisien Jalur). Menurut Sholiha (2015), koefisien jalur atau path coefficients menggambarkan kekuatan hubungan antar konstruk. Nilai path coefficients memiliki standar dari -1 untuk mengidentifikasi hubungan negative sampai +1 untuk mengidentifikasi hubungan positif. Sholiha (2015) menyatakan bahwa metode bootstrap melakukan pengambilan sampel dengan cara sampel data yang dikembalikan (resampling with replacement $) . \mathrm{KI}=0.429 \mathrm{KO}+0.271 \mathrm{MO}+0.309 \mathrm{KK}$.

Hasil Uji Hipotesis. dalam pengujian hipotesis, peneliti dapat memperhatikan t statstic dan $p$-values. Jika t statistic $\geq 1,960$ dan p-values $\leq 0,050$ maka dapat disimpulkan pengaruh tersebut signifikan, dapat disimpulkan hasil pengujian hipotesisnya adalah :

Hipotesis yang pertama adalah sebagai berikut:

$\mathrm{H}_{1}$ : Terdapat pengaruh kompensasi terhadap kinerja karyawan.

Berdasarkan hasil pada Tabel 4.16, variabel kompensasi terbukti berpengaruh terhadap kinerja karyawan. Hal ini dibuktikan dengan nilai $t$ statistics sebesar 4,115 yang lebih besar dari cut off value sebesar 1,96. Kemudian $p$ values yang dihasilkan adalah sebesar 0,000 lebih kecil dari cut off value yang ditetapkan yaitu sebesar 0,05. Sehingga dapat disimpulkan bahwa $\mathrm{H}_{1}$ tidak ditolak.

Hipotesis yang kedua adalah sebagai berikut:

$\mathrm{H}_{2}$ : Terdapat pengaruh motivasi terhadap kinerja karyawan.

Berdasarkan hasil pada Tabel 4.16, variabel motivasi terbukti berpengaruh terhadap kinerja karyawan. Hal ini dibuktikan dengan nilai $t$ statistics sebesar 2,922 yang lebih besar dari cut off value sebesar 1,96. Kemudian $p$ values yang dihasilkan adalah sebesar 0,004 lebih kecil dari cut off value yang ditetapkan yaitu sebesar 0,05. Sehingga dapat disimpulkan bahwa $\mathrm{H}_{2}$ tidak ditolak.

Hipotesis yang ketiga adalah sebagai berikut:

$\mathrm{H}_{3}$ : Terdapat pengaruh kepuasan kerja terhadap kinerja karyawan.

Berdasarkan hasil pada Tabel 4.16, variabel kepuasan kerja terbukti berpengaruh terhadap kinerja karyawan. Hal ini dibuktikan dengan nilai $t$ statistics sebesar 2,823 yang lebih besar dari cut off value sebesar 1,96. Kemudian $p$ values yang dihasilkan adalah sebesar 0,005 lebih kecil dari cut off value yang ditetapkan yaitu sebesar 0,05. Sehingga dapat disimpulkan bahwa $\mathrm{H}_{3}$ tidak ditolak.

\section{DISKUSI}

Setelah mengetahui hasil hipotesis diatas maka dapat disimpulkan bahwa variabel independen yaitu kompensasi, motivasi dan kepuasan kerja terbukti mempunyai pengaruh positif signifikan terhadap kinerja karyawan. Dengan pengaruh paling besar adalah kompensasi terhadap kinerja.

\section{KESIMPULAN}


Berdasarkan pembahasan yang telah dilakukan sebelumnya, maka dapat diambil kesimpulan bahwavariabel kompensasi, motivasi dan kepuasan kerja memiliki pengaruh positif dan signifikan terhadap kinerja karyawan. Variabel yang memiliki pengaruh paling besar terhadap kinerja karyawan adalah kompensasi, maka kompensasi perlu diperhatikan oleh atasan PT. Kunia Mandiri Jaya.

\section{SARAN}

Berdasarkan hasil dan kesimpulan yang telah diperoleh, penulis mencoba memberikan beberapa saran, sebagai berikut:

a. Dari hasil olah data kuisioner kompensasi karyawan, dapat disimpulkan bahwa PT. Kurnia Mandiri Jaya perlu untuk meningkatkan pemberian bonus kepada karyawan apabila hasil pekerjaan melebihi target yang telah ditetapkan. Pimpinan bisa memberikan apresiasi yang lebih atas prestasi kerja karyawan dalam bentuk bonus berupa uang ataupun fasilitas.

b. Hasil olah data kuisioner motivasi karyawan, dapat disimpulkan bahwa para manajer di PT. Kurnia Mandiri Jaya perlu untuk memotivasi karyawan untuk selalu terlibat dan termotivasi dengan kerjasama tim dalam menyelesaikan suatu pekerjaan.

c. Hasil olah data kuisioner kepuasan kerja dapat disimpulkan bahwa manajer PT. Kurnia Mandiri Jaya perlu mengevaluasi agar karyawan merasa puas pada saat membantu rekan kerja dalam menyelesaikan masalah.

\section{DAFTAR RUJUKAN}

A., Anwar Prabu Mangkunegara, 2013, Manajemen Sumber Daya Manusia Perusahaan. Bandung: Remaja Rosdakarya.

A.M., Sardiman, 2011, Interaksi dan Motivasi Belajar Mengajar. Jakarta: Rajawali Press.

Abdillah, Willy \& Jogiyanto, 2015, Partial Least Square (PLS) Alternatif Structural Equation Modeling (SEM) dalam Penelitian Bisnis. Ed.1. Yogyakarta: ANDI.

Adnyani, \& Nurcahyani, 2016, Pengaruh kompensasi dan motivasi terhadap kinerja karyawan dengan kepuasan kerja sebagai variable intervening pada PT. Sinar Sosro Pabrik Bali. E-Jurnal Manajemen Unud: ISSN 2302-8912 Vol. 5, No.1.

Gomes, Faustino Cardoso., 2010, Manajemen Sumber Daya Manusia, Yogyakarta: Andi Offset.

Hasibuan, Malayu. S. P., 2017, Manajemen Sumber Daya Manusia. Edisi Revisi. Jakarta: Bumi Aksara.

Husain, Ananda S., 2015, Penelitian bisnis dan manajemen menggunakan partial least squares (PLS) dengan smart PLS 3.0. Modul ajar jurusan manajemen fakultas ekonomi dan bisnis Unversitas Brawijaya.

Inuwa, 2016, Job satisfaction and Employee Performance: An Empirical Approach Nonacademic staff of Bauchi State University Gadau Nigeria. The Millennium University Journal: Vol. 1, No. 1; 2016, ISSN 2225-2533

Komara, \& Nelliawati, 2014, Pengaruh Kompensasi, Motivasi dan Kepuasan Kerja terhadap Kinerja Karyawan Pegawai Negeri Sipil di Lingkungan Rumah Sakit Umum Daerah Kota Bandung. Jurnal Ekonomi, Bisnis \& Entrepreneurship: Vol. 8, No. 2, Oktober 2014, 73-85 ISSN 2443-2121.

Malhotra, Naresh, 2015, Basic Marketing Research. England: Pearson Education.

Mustafa, Zainal \&Wijaya, T., 2012, Panduan Teknik Statistik SEM \&. PLS dengan SPSS AMOS. Cahaya Atma Pustaka: Yogyakarta. Firdaus, Usman. 
Nawawi, 2011, Manajemen Sumber Daya Manusia: Untuk Bisnis Yang Kompetitif. Yogyakarta: Gajahmada University Press.

Nawawi, M. T., 2015, Pengaruh Kepuasan Kerja, Dan Motivasi Kerja Terhadap Kinerja Karyawan/ti Dengan Komitmen Organisasional Sebagai Variabel Intervening (Studi Karyawan Outsourcing PT. J Yang Ditempatkan Di Kampus II Untar Jakarta). Jurnal Manajemen Bisnis Indonesia: Vol 3 No 1 -Edisi Oktober 2015

Nikensari, 2018, The effect of Compensation, Motivation of Work Employee and Work Satisfaction to Employee Performance Employees of PT. BANK XYZ (PERSERO) Tbk. Academy of Strategic Management Journal: Volume 17, Issue 4.

Okwudili, \& Ogbu, 2017, The Effect of Compensation on Employee Performance in Nigeria Civil Service: A Study of Rivers State of Internal Revenue Service. Journal of Strategic Human Resource Management: Volume 6 Issue 2, June 2017.

Olusadum, \& Anulika, 2018, Impact of Motivation on Employee Performance: A Study of Alvan Ikoku Federal College of Eduaction. Journal of Management and Strategy: Vol. 9, No. 1; 2018.

Pamela, Akinyi Omollo., 2015, Effect of motivation on employee performance of commercial banks in Kenya: A case study Workers of the Kenya Commercial Bank in Migori County. International Journal of Human Resource Studies. ISSN 2162-3058 2015, Vol. 5, No. 2.

Panchal, 2016, The Impact of Job Satisfaction; While Performing Responsibilities Employees who work at the twenty-four stores within Kepong area, Wilayah Persekutuan, Kuala Lumpur. International Research Journal of Engineering and Technology: Volume 3, Issue 7, July -2016.

Rivai, Veithzal, 2011, Manajemen Sumber Daya Manusia Untuk Perusahaan Dari Teori Ke Praktek. Bandung: Rajagrafindo persada.

Sholihah, Z.S \& Afriansyah, E.A., 2017, Analisis Kesulitan Siswa Dalam Proses Pemecahan Masalah Geometri Berdasarkan Tahapan Berfikir Van Hiele. Jurnal Mosharafa: Vol (6) 2.

Siagian. Sondang. P., 2012, Manajemen Sumber Daya Manusia. Bumi Aksara. Jakarta.

Sugiyono, 2017, Metode Penelitian Kuantitatif, Kualitatif, dan R\&D. Bandung: Alfabeta, CV.

Sutrisno, Edy., 2013, Manajemen Sumber Daya Manusia, Jakarta: Kencana Pernada Media Group.

Wibowo, 2011, Manajemen Kinerja. Edisi Ketiga. Jakarta: PT Raja Grafindo Persada.

Winardi, 2015, Manajemen Prilaku Organisasi, Edisi Revisi. Jakarta: Prenada Media Group.

Yamin, Sofyan, \& Heri Kurniawan, 2011, "Generasi Baru Mengolah Data Penelitian dengan partial Least Square Path Modeling”, Jakarta: Salemba Infotek. 